\title{
COMENTARIO SOBRE "SENADO TERRITORIAL Y PRESENCIA DE NOTABLES»
}

\author{
PEDRO J. GONZÁLEZ TREVIJANO \\ Catedrático de Derecho Constitucional \\ Universidad de Extremadura
}




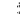




\title{
COMENTARIO SOBRE «SENADO TERRITORIAL Y PRESENCIA DE NOTABLES»
}

\author{
POR \\ PEDRO J. GONZÁLEZ TREVIJANO \\ Catedrático de Derecho Constitucional \\ Universidad de Extremadura
}

Es habitual que en la elaboración de una nota sobre una monografía, medie siempre un cierto conocimiento $y$, en ocasiones, una determinada relación con el autor del libro o trabajo que se pretende, siquiera sea de una manera sucinta, comentar y enjuiciar. $Y$ éste es el caso que nos ocupa. Conozco al Profesor Doctor José Manuel Vera Santos desde hace ya algunos años, cuando iniciaba su andadura universitaria en el Centro de Estudios Ramón Carande (CEESJ), dependiente de la Universidad Complutense, así como su época de brillante alumno en el Centro de Estudios Políticos y Constitucionales, del que es diplomado en Ciencia Política y Derecho Constitucional. Conozco los esfuerzos, los desvelos y la dedicación generosa en la elaboración de su tesis doctoral, que obtuvo la máxima calificación de "Apto cum laude por unanimidad", leída en la Facultad de Derecho de la Universidad Complutense en el mes de junio de 1996, y de cuyo Tribunal, presidido por el profesor Jorge de Esteban e integrado por los profesores Solozábal Echevarría, Carreras Serra, Pérez-Bustamante, tuve el placer de formar parte. $Y$, por último, conozco, asimismo, la reelaboración minuciosa, paciente y satisfactoria de su tesis de grado, que es la que hoy 
se publica por la Dirección de Estudios y Documentación del Senado, iniciando así una colección que esperemos se consolide en la siempre necesaria labor de promoción y estudio de las materias políticas y constitucionales.

El objeto de estudio del profesor Vera es un análisis valiente y crítico - quiero resaltar esta especial significación de su Obra, ya que no es habitual en las Tesis doctorales al uso- sobre la insatisfactoria composición y funciones de nuestra Cámara Alta. La argumentación que se defiende - dicho sea, además, con la pasión de quien cree mantener una idea digna de luchar por ella- es la de territorializar el Senado, a fin de llegar a constituirse, de acuerdo con el imperativo constitucional del artículo 69, en auténtica Cámara de representación territorial, pero con la peculiaridad de incorporar a su composición un contingente de personalidades notables. De aquí el título de la presente monografía: Senado territorial y presencia de notables. Razonamiento y exposición que se desarrolla con una prosa sencilla, cuidada y comprensible, sin por ello dejar de ser exigente y con un buen dominio de la terminología jurídica, a lo largo de los tres capítulos en que se estructura la obra.

El primero de los capítulos está centrado en el estudio de la composición del Senado en el Derecho histórico español desde los tiempos del Estatuto de Bayona de 1808 y el Decreto de 1810. El segundo, dedicado al examen de la composición del Senado a lo largo del iter constituyente del artículo 69 de la Constitución, sin olvidar la relevancia, como precedente de relevancia indiscutible, de la Ley para la Reforma Política de 1976. Y el tercero, atento a la exposición de los diversos modelos en el Derecho comparado que articulan una Cámara Alta con una presencia de notables. Por último, el libro se cierra con unas conclusiones teóricas y con la propuesta de una reforma constitucional. Como vemos, nos hallamos ante un objeto de investigación tratado de una manera exhaustiva, en el que se hacen las debidas referencias al Derecho histórico español, al Derecho comparado y al Derecho constitucional vigente. Sin que podamos olvidar, insistimos de nuevo, una especialidad propia del presente trabajo: su valentía para no ceñir su estudio a un análisis meramente expositivo, sino adelantar un juicio no sólo critico de la institución de referencia, sino formulando una solución de lege ferenda. Pero detengámonos, siquiera sea sucintamente, en el examen del contenido concreto de los capítulos apuntados.

Así, decíamos, que el primer capítulo se ceñía al estudio del Derecho histórico español (páginas 31 a 118), tras la elaboración de una pormenorizada y aclaratoria diferenciación entre las diferentes clases de senadores, atendiendo a las siguientes circunstancias: 
1) A las condiciones de adquisición. A tal efecto se diferencian, entre otras, las categorias de senadores natos o por derecho propio (por razones de empleo o por su relación familiar con el monarca) y senadores electos, ya lo sean popularmente (por sufragio directo o indirecto) o en elección doble y consecutiva.

2) A las condicioneś de duración del mandato. Para ello se distingue entre los senadores temporales stricto sensu (limitados por un plazo determinado), senadores temporales lato sensu (sometidos a una condición resolutoria consistente en el mantenimiento en el empleo y la calidad) y los senadores vitalicios o no limitados temporalmente.

3) A las condiciones o no de transmisibilidad del cargo. A tal efecto, se diferencia entre senadores que pueden transmitir su cargo por herencia, frente a aquellos otros que no lo pueden hacer.

Pues bien, este esquema, con el que se pretende, y se consigue con innegable éxito, aclarar la confusa terminología doctrinal existente sobre el tema, se va estudiando al hilo de todos y cada unos de nuestros textos y proyectos constitucionales desde el siglo $x \mathrm{IX}$ hasta nuestros días. A saber: el Estatuto de Bayona (arts. 32.1 y 2, y 34); el Estatuto Real de 1834 (arts. 3, 5, 6 y 7); el Proyecto de Constitución de la Sociedad isabelina (arts. 19, 20 y 23); el Proyecto constitucional de Istúriz (art. 17); la Constitución de 1837 (arts. 15, 19 y 20); la Constitución de 1845 (arts. 14, 15, 17 y 18); los Proyectos constitucionales de Bravo Murillo (arts. 1, 2, 4 y 5); el Proyecto de Roncali (arts. 15, 16 y 17); la Constitución non nata de 1856 (arts. 18 y 23); el Acta Adicional de O'Donnell (arts. 14, 15, 17 y 18); la Reforma de Narváez de 1857 (arts. 14, 15, 17 y 18); la Ley Món (arts. 14, 15, 18 y disposición transitoria); la Constitución de 1869 (arts. 60 y 64); el Proyecto. Federal de 1873 (art. 53); la Constitución de 1876 (arts. 20.2, 21 y 2, y arts. 1 y 2 de la Ley de Elección de Senadores de 1876); el Anteproyecto de Constitución de 1931 (arts. 33, 37 y 38), y el Proyecto de Reforma de 1935.

En cuanto al segundo de los Capítulos, se examina, de forma certera, la composición del Senado en la tramitación constituyente, desde el estudio de la Ley para Reforma Política hasta la elaboración del artículo 69 de nuestra Carta Magna (páginas 119 a 205). En dicho análisis se hace hincapié en su tratamiento constitucional en las diferentes fases de la tramitación constituyente, atendiendo a las diversas clases de senadores, duración del cargo, número, circunscripción electoral y escrutinio. Veamos, aunque sea a muy grandes rasgos, los diversos textos y el tratamiento dado a la elección y composición del Senado durante la tramitación constituyente apuntada: 
1) En la Ley para la Reforma Política (art. 2) se reconocen dos modalidades de senadores: los senadores elegidos por elección popular directa, en un número de doscientos siete, a través de un sufragio mayoritario de voto múltiple restringido, de circunscripción provincial, y los senadores por elección real, que no podían exceder de la quinta parte de los elegidos popularmente, en un número final de cuarenta y uno.

2) El Borrador Constitucional y el Anteproyecto de Constitución (arts. 59 y 60, respectivamente). Así en el Anteproyecto de Constitución sólo se reconocían los senadores elegidos de manera popular de una manera indirecta, bien sea por las Asambleas Legislativas de los Territorios Autónomos (un senador por Territorio Autónomo y uno más por provincia integrada en dicho Territorio y un senador cada 250.000 habitantes o fracción superior a la mitad de dicha cifra), el Congreso de los Diputados o los concejales municipales en el caso transitorio de que no se hubiesen incorporado a Territorio Autónomo alguno. Por su parte, el Anteproyecto de Constitución modificó algunos extremos referidos a la categoria de senadores: los senadores elegidos por las Asambleas de los Territorios Autónomos son elegidos "de entre" $y$, por lo tanto, no sólo "por" los propios miembros de la Asamblea designante (diez senadores por Territorio Autónomo, duplicándose el criterio poblacional reseñado en el Borrador Constitucional); el Congreso de los Diputados podía nombrar hasta veinte senadores, requiriéndose para ello el acuerdo por tres quintas partes de votantes que superase, en todo caso, la mayoría absoluta de la Cámara Baja, así como la fijación de una serie de baremos generales para acceder a tal nombramiento.

Por lo demás, también se recogen las enmiendas presentadas al artículo 60 y a la Disposición Transitoria Quinta del Anteproyecto Constitucional por parte de los señores Carro Martínez, Rosón Pérez, López Rodó y Ortí Bordás.

3) Roto el consenso entre las diferentes formaciones políticas constituyentes, que se vislumbra muy bien, como acertadamente resalta el autor, en el propio Informe de la Ponencia constitucional, se produciría lo que, a juicio del profesor Vera, supone la llamadan transustanciación de la composición del Senado" (art. 64 DCC), y que provocaría la desaparición de la figura del senador que es elegido por sus relevantes méritos, ya lo fuera por el Rey o por el propio Congreso de los Diputados, a pesar de las innumerables enmiendas presentadas en favor de su mantenimiento; $y$, lo que es más importante, el modelo más autonomista de la Cámara Alta diseñado en el Borrador Constitu- 
cional y en el Anteproyecto de Constitución da paso a un sistema híbrido de fuerte prevalencia provincial sobre la propia dimensión territorializada de las Comunidades Autónomas. Por lo demás, dentro del tratamiento exhaustivo del trabajo que venimos reseñando se exponen y enjuician las enmiendas que en la propia Cámara Alta abogaban por la elección-designación directa por el monarca (señores Iglesias Corral, Primo de Rivera y Urquijo y Zarazaga Bustillo), por cooptación (Sánchez Agesta), por elección doble y consecutiva (Carlos Ollero), por derecho propio en virtud de ostentación de cargo anterior (Señor Primo de Rivera y Urquijo) y la elección indirecta por las Asambleas legislativas de las Comunidades Autónomas (Entesa dels Catalans).

4) Este último modelo es el que se terminará por consagrar en el definitivo artículo 69 de la Constitución, tras los oportunos matices introducidos en el Senado y en la Comisión Mixta Congreso de los Diputados-Senado. Precepto que, como señala el autor, «recuerda sobremanera lo prescrito en la LRP, con la introducción del cambio de senadores que eran elegidos por el Rey por un número similar de senadores designados por las Asambleas de las Comunidades Autónomas."

Por lo que concierne al capítulo tercero (páginas 209 a 269), en él se recogen diferentes modelos de Derecho comparado que acogen, con sus propias peculiaridades, un Senado o Cámara Alta con presencia de notables. Así se analizan los siguientes modelos:

1) El modelo francés, desde la Constitución de 1795 al vigente Texto constitucional de 1958 (arts. 24 y 25), algunos de cuyos miembros son elegidos por el procedimiento de cooptación de representantes de intereses diferentes a los que califican el Senado como Cámara de representación territorial.

2) El modelo italiano, desde el Estatuto albertino de 1848 a la Constitución de 1947 (arts. 57, 58 y 59.), donde conviven dos modalidades de senadores: senadores por derecho propio como consecuencia de la ostentación de un cargo anterior y senadores designados por el Jefe del Estado dentro de una Cámara regional.

3) El modelo belga, con la Constitución de 1831, y sus reformas que ahora importan, de 1968, 1971, 1993 y 1995 (arts. 67 y 68), en el que tienen presencia senadores por derecho propio en virtud de su relación con la Corona y senadores elegidos por cooptación en el Senado federal belga.

El capítulo tercero se cierra con unas interesantes páginas en que se aclaran y clasifican las diferentes modalidades de senadores, 
según los distintos criterios de cooptación, por derecho propio y por elección directa por el Jefe del Estado, al hilo de cuya exposición se dedican asimismo unas atinadas páginas al examen de la institución del refrendo.

Llegados a este punto, el libro se completa con unas pormenorizadas y claras conclusiones (páginas 273 a 281), atreviéndose el autor, incluso, a formular, en el sentido defendido de la presencia de un número de notables en nuestra Cámara Alta, una propuesta de reforma constitucional (páginas 281 a 290). Ahora bien, quiero dejar constancia del aplauso que merece la inclusión de conclusiones al final de cada uno de los capítulos reseñados. Con ello, no sólo se facilita en mucho la labor de lectura y estudio del trabajo, sino que estoy convencido de que mejoró en su día la calidad de la propia obra, ya que al redactarlas, el autor se debió ver obligado a revisar y poner en tela de juicio algunos de los contenidos y opiniones inicialmente vertidas en sus capítulos. Pues bien, la propuesta y conclusión del autor es bien clara: su apuesta por la incorporación al Senado español de una serie de personalidades notables.

A juicio del profesor Vera, la preservación del principio de territorialidad del Senado no se vería afectada, como pueda pensarse quizás en un primer momento, por el acceso a nuestra Cámara Alta de una serie de senadores "no territoriales" en cuanto a su origen, "ya que desde el prisma de sus competencias y funciones, obviamente representarán intereses territoriales si así lo permite el elenco competencial atribuido al colegio del que forman parte». Y finaliza diciendo: "Nuestra propuesta de inclusión en el Senado de notabilidades sociales y políticas no empece dicha calificación (se refiere a la territorialidad de la Cámara Alta), ya que numéricamente los notables que accedan al Senado (cualquiera que sea la vía utilizada) suponen una mínima parte de los componentes del colegio. En cuanto a la funcionalidad del mismo, estas notabilidades de la vida pública coadyuvarán en la función territorial $y$ en cualquiera de las otras a cumplir por el colegio del cual estos senadores que proponemos forman parte, así como perfeccionarán y mejorarán las relaciones intergrupales y favorecerán la relación entre el Senado y la sociedad". Opinión, por cierto, que también postula el director de su tesis, el profesor Jiménez de Parga, quien en el prólogo del libro argumenta en favor, no sólo de la clásica "legitimación de origen», sino también en lo que denomina "legitimación de ejecutoria", entendida "como la habilitación para un cargo u oficios públicos en virtud de la buena labor realizada en otro u otros, o del admirable quehacer cívico sin haber ocupado poltrona alguna". 
La incorporación de esta presencia de notables en el Senado encontraría una fundamentación complementaria en dos órdenes de razones. En primer lugar, en la multiplicidad de funciones del Senado, tales como el ejercicio de las funciones presupuestarias, de control político y de nombramiento de integrantes de otras instituciones del Estado, más allá de la función territorial, por muy relevante o incluso definitoria que ésta pudiera entenderse. $Y$ en segundo término, tales senadores desplegarían una importante labor, tanto ad intra como ad extra, tanto como amigables componedores ante desacuerdos motivados por cuestiones meramente electorales y vía de acceso de propuestas de estudio que difícilmente llegarían a la Cámara, como por la incorporación al Parlamento de personalidades relevantes provenientes de la vida social y política.

Así las cosas, se finaliza por presentar una reforma constitucional, mejor dicho tres opciones de reformas constitucionales alternativas, al hilo de la incorporación de ciertos notables en el Senado. Tales propuestas de revisión del artículo 69 de la Constitución son las siguientes:

1) La concesión de la calidad de senador vitalicio, de ser su deseo, de quienes hayan ocupado el cargo de Presidente del Gobierno. Sólo cabe su revocación por sentencia judicial firme privativa de los derechos políticos del interesado.

2) La elección por el propio Senado, una vez constituido, de diez senadores distinguidos en los ámbitos social y político. Su duración será la misma que la de la legislatura, pudiendo ser reelegibles.

3) La designación por el monarca de diez senadores en virtud de sus destacados méritos sociales y políticos. Su mandato se encontrará limitado temporalmente, coincidiendo con la duración de la legislatura, siendo posible su reelección.

Por último, el trabajo se cierra con una exhaustiva, a la vez que cuidada, selección bibliográfica (páginas 292 a 314), tanto de la doctrina española como comparada, sobre el tema. Monografía que se añade, de esta manera, a otros trabajos de los que el profesor Vera es coautor, tales como unas "Lecciones de Derecho Constitucional» (Tecnos, Madrid, 1995) y "Legislación Electoral" (Tecnos, 1996).

En resumidas cuentas, el juicio de la presente monografía no puede ser, como hemos tenido ocasión de reiterar a lo largo de esta recensión, más que muy favorable. Estamos en presencia de una investigación realizada desde el rigor, la exigencia personal y la dedicación. 
De un trabajo que bebe en las mejores fuentes bibliográficas, tanto de la literatura constitucional española como de la doctrina extranjera. $Y$ de un libro escrito en un lenguaje en el que, dominando la técnica y las categorías jurídicas, siempre se nos muestra como sencillo y accesible. Buena prueba, esto último, de la comprensión y claridad de ideas sobre el tema por parte del autor. 